\title{
The effectiveness of mobile learning in the teaching and learning of probability
}

\author{
Durga Gnanasagaran ${ }^{1 *}$, Abdul Halim Amat @ Kamaruddin ${ }^{2}$ \\ ${ }^{1}$ Department of Mathematics Perak Matriculation College \\ ${ }^{2}$ Faculty of Science and Mathematics Sultan Idris Education University \\ *email: durga.gnanasagaran@gmail.com
}

DOI: https://doi.org/10.37134/jpsmm.vol9.2.2.2019

Published: 06 December 2019

\begin{abstract}
This study investigates the effectiveness of mobile learning in the teaching and learning of Probability. The context of mobile here is not just restrained to gadgets such as smartphones but also the fact that teaching and learning can occur beyond boundaries and anywhere according to the convenience and personal preference of the students. This study made use of the pretest - posttest quasi experimental design and the students chosen for the study were from a pre-university college located in the northern region of the country. A total of 92 students made up the sample of the study. There were 46 students each in the experimental and control groups respectively. Cluster random sampling was employed as the sampling method here. The instrument used to collect data with the aim of strengthening the outcome of the study was the achievement test. A quantitative approach was undertaken specifically to analyse the obtained data. The paired sample t-test and independent sample t-test were executed in the data analysis process. Initially, every student involved in the study regardless of the group they were in possessed equal strength in their understanding of the content being covered as indicated by the results of their pre-test. The paired sample t-test yielded $p<0.05$ which meant that there was a significant difference between the mean score of the pre-test and post-test in the experimental group and control group respectively. The outcome of the independent sample t-test showed that there was a significant difference between the mean score of the experimental group and that of the control group in the posttest $(p<0.05)$. This indicated that the treatment via mobile learning had indeed played a role in the improved performance of students in Probability, hence proving the effectiveness of mobile learning in the teaching and learning of Probability.
\end{abstract}

Keywords: Mobile learning, multimedia, video

Scope: Mathematics Education

\section{INTRODUCTION}

The introduction is mainly to underline the important points of this study. How mobile learning affects performance of pre-university students will be analysed in this study with reference to their achievement in a test on the chapter probability. Probability is a chapter contained in the subject of mathematics. The existence of internet, smartphones and various applications has changed the whole idea of teaching and learning mathematics today, giving it the opportunity to move from conventional practices to the introduction of mobile learning.

Mobile learning is a learning platform using wireless technology in the world of education. This platform enables learning without boundaries and gives students the liberty to learn at their own convenience (Muasaad, 2014). An important factor that greatly contributes to the success of this manner of learning is its productivity. A wholesome multimedia content would increase students' understanding on the subject matter and in return would give room for an increased result in the learning process experienced by them. 


\section{Problem Statement}

According to the Mathematics Candidate Work Report of the semester examination, many students from the Module 3 Science Stream were unable to correctly answer questions related to conditional probability, continuous probability distribution and normal distribution. Module 3 Science Stream students are those whose subject package consists of Mathematics, Biology, Chemistry and Computer Science. This report also stated that students' failed to interpret the questions well, namely the long wordy ones. Students could not draw the Venn Diagram, tree diagram and contingency table correctly to assist them in interpreting the information given in the question and they also faltered in deducing independent probability cases. Due to this report, a quiz was conducted to determine whether or not students truly mastered the basic concepts of probability. The analysis of the quiz showed a low level of conceptual understanding and problem solving skills with regards to probability among these students.

\section{Study Objective}

The study aims to find the effectiveness of mobile learning by establishing the difference in performance between students who were given the lessons on probability solely via traditional method as compared to the students who were given the lesson using multimedia in the form of a video which they can have access to anywhere through their mobile devices.

\section{Terminology}

a) Mobile learning: The context of mobile here is not just restrained to gadgets such as smartphones but also the fact that teaching and learning can occur beyond boundaries and anywhere according to the convenience and personal preference of the students.

b) Students' performance: Students' mean score in the pre-test and post-test administered before and after the treatment in both the control and treatment groups.

c) Multimedia: A representation of subject content that combines elements such as text, voice, pictures, diagrams, graphs and simulation involving visualisation and hearing.

\section{LITERATURE REVIEW}

This section gives an overview of the literature reviewed for the study. Evidences are put forth based on previous research findings on the subject of mobile learning preferences.

\section{Mobile Learning Preferences}

There has been many researches pertaining to perception regarding mobile learning in teaching and learning. However, there exists a gap in the section exploring the effectiveness of mobile learning in relation to performance of students in the particular subject. They include the ability to access information quickly.

An insight into students' perception of mobile learning, but this time at university level was put forth by Syed Roohullah et al (2016). They observed that a substantial good margin of students were in favour of mobile learning with majority of the students leaning towards mobile technology for learning. The main reason outlined was due to mobile learning providing an independent learning environment due to the mobile nature of the devices and instant access to the materials. 
It is safe to say that more applicable and efficient studies in this area need to be carried out. Experimental studies may be considered more useful given the nature of education trends in today's day and age. Studying perception alone is not enough to uncover whether or not mobile learning is a successful move and hence, the gap in this department need to be fulfilled to make the mobile learning approach a more wholesome one. In a nutshell, although mobile learning is still in its infancy, it is certainly gaining momentum.

\section{METHODOLOGY}

This section outlines and justifies the methods of data collection and data analysis decided upon for this study.

\section{Research design}

This study made use of the pretest - posttest quasi experimental design to test the effectiveness of mobile learning in the teaching and learning of probability. A few threats which may influence the results were given attention to. The same lecturer acted as the facilitator. Both groups used same notes on the topic of probability. The control group used the set of notes prepared in hardcopy version while the experimental group used the mobile multimedia prepared based on the same notes. In other words, both groups underwent lessons with the same lesson plan and the only difference was that the experimental group's teaching and learning happened via mobile multimedia whereas the control group experienced the traditional teaching and learning method. Besides that, the time allocated for each group was the same. A pre-test to gauge the students' prior knowledge on their understanding and basic skills pertaining to probability was done before the start of the treatment.

\section{Population and Sampling}

From 350 students in Module 3 of the Science Stream in the pre-university college located in the northern region of the country where the study took place, a sample of 46 students to make up the experimental group and another 46 students to make up the control group were identified.

\section{Study Instrument}

This study made use of the pre and post achievement tests to collect data. The achievement test constructed was adapted from various Matriculation Mathematics reference books that complied with the syllabus specification and learning outcomes of the Malaysian Matriculation course. This instrument was then used to measure performance of students in probability. Students' understanding of probability, namely that of the basic concepts, independent and non-independent cases, their ability to draw the tree diagram and contingency table as well as conditional probability were examined. Both tests assessed the same scopes and had the same level of difficulty.

\section{Test Specification Table}

Before the construction of items in the test took place, a Test Specification Table which is known as the test blueprint was developed.

\section{Validation of Instrument}

With regards to an achievement test, content validity ensures whether or not the items in the test accurately assesses what is intended to be known. Undeniably, this is 
exceptionally important with achievement tests. Both the pre-test and post-test assessed the same scopes and had the same level of difficulty. The questions constructed were referred to two experts in the field specialising in the content of probability and statistics at pre-university level to be inspected in terms of its validity. The Cohen's Kappa value reported was 1.00, signifying perfect agreement between the experts about the validity of the tests' content (refer to Appendix E). This indicated that the achievement test designed was perfectly valid and fit to be administered.

\section{Pilot Study}

Pilot test involving 15 students each in the experimental and control group was carried out and it's reliability coefficient computed by using Cronbach Alpha Procedure. The students selected for the pilot study were from a pre-university college located in the northern region of the country. They were Science stream students doing the one-year matriculation programme at the college which requires them to take Mathematics as one of their core subjects. Probability is one of the chapters in the Mathematics syllabus taken by the students.

Reliability can be thought of as consistency (Sekaran, 2000). An achievement test is reliable if the Cronbach's Alpha value reported is greater than 0.7. The Cronbach's Alpha value in the case of this study gave a value of 0.792 (refer to Appendix F). This value indicated a strong reliability of the instrument. The high Cronbach Alpha coefficient also portrayed that the students could understand the items in the achievement test well.

\section{Validity and Reliability of Instrument}

Looking at the values of the Cohen's Kappa coefficient and that of Cronbach's Alpha, it is safe to say that the pre and post achievement tests designed for this study was valid and reliable. A useful instrument is one which has a high level of validity as well as reliability and that is definitely a crucial component in ensuring the quality of the research on a whole.

\section{FINDINGS}

This section shows the analysis done on the data collected. Appropriate tests were carried out in order to examine whether mobile learning was effective in the teaching and learning of probability. The results of the pre and post achievement tests were statistically analysed with the four hypothesis questions in mind.

\section{$\mathrm{H}_{01}:$ There is no significant difference between the mean score of the xperimental group and that of the control group in the pre-test.}

The result of the independent sample t-test showed that there was no significant difference between the mean score of the experimental group $(\mathrm{M}=5.50, \mathrm{SD}=1.74)$ and that of the control group ( $\mathrm{M}=4.85, \mathrm{SD}=1.79)$ in the pre-test; $[\mathrm{t}(90)=1.775, \mathrm{p}=0.079]$. Failed to reject $\mathrm{H}_{01}$.

This was due to the fact that both the experimental and control groups were equally on par in their content knowledge pertaining to probability at the initial stage before the treatment was administered. In a nutshell, the homogeneity amongst the experimental and control groups were established before the intervention took place. Therefore, the null hypothesis $\mathrm{H}_{01}$ : There is no significant difference between the mean score of the experimental group and that of the control group in the pre-test stands. 


\section{$H_{02}:$ There is no significant difference between the mean score of the xperimental group and that of the control group in the post-test.}

The result of the independent sample t-test showed that there was a significant difference between the mean score of the experimental group $(\mathrm{M}=9.50, \mathrm{SD}=3.23)$ and that of the control group $(\mathrm{M}=7.65, \mathrm{SD}=1.90)$ in the post-test; [t$(90)=3.344, \mathrm{p}=0.001]$.

It could clearly be seen here that on average, the experimental group produced better results as compared to the control group. Therefore, $\mathrm{H}_{02}$ : There is no significant difference between the mean score of the experimental group and that of the control group in the posttest is rejected. With the existence of a statistically significant difference in the scores here, it is wise to conclude that the higher mean score obtained by the experimental group is contributed by the usage of mobile learning in the teaching and learning of probability. Hence, it is obvious that mobile learning has indeed brought about the improvement in the understanding and comprehension of probability.

$\mathrm{H}_{03}:$ There is no significant difference between the mean score of the pre-test and post-test in the control group.

The paired sample t-test was administered to test the third null hypothesis, $\mathrm{H}_{03}$ : There is no significant difference between the mean score of the pre-test and post-test in the control group. 46 students made up the sample of the control group. The paired sample t-test here revealed that the students performed better in the post-test $(\mathrm{M}=7.65, \mathrm{SD}=1.90)$ as compared to how they fared in the pre-test $(\mathrm{M}=4.85, \mathrm{SD}=1.79)$; $[\mathrm{t}(45)=-7.635, \mathrm{p}=0.000 \leq 0.05]$. This resulted in the rejection of the third null hypothesis here.

The result of the paired sample t-test shows that there is a significant difference between the mean score of the pre-test $(M=4.85, S D=1.79)$ and post-test $(M=7.65, S D=1.90)$ in the control group; $[\mathrm{t}(45)=-7.635, \mathrm{p}=0.000]$

\section{$H_{04}:$ There is no significant difference between the mean score of the pre-test and post-test in the experimental group.}

Subsequently, the paired sample t-test was carried out for the experimental group as well where another 46 students formed the sample. The results obtained from the post-test $(\mathrm{M}=9.50, \mathrm{SD}=3.23)$ were significantly better than that of the pre-test $(\mathrm{M}=5.50, \mathrm{SD}=1.74)$; $[\mathrm{t}(45)=-7.875, \mathrm{p}=0.000 \leq 0.05]$. Hence, it is fair to say that there was a statistically significant difference between the mean score of the pre-test and the post-test in the experimental group. This could be due to the teaching and learning of probability that took place with the incorporation of mobile learning. The fourth null hypothesis, $\mathrm{H}_{04}$ : There is no significant difference between the mean score of the pre-test and post-test in the experimental group is therefore rejected.

\section{DISCUSSION OF OUTCOMES FROM ANALYSIS UNDERTAKEN}

The results obtained from the study significantly showed the positive impact of mobile learning in the teaching and learning of Probability. Data used in this study was collected via the results of the pre and post achievement tests. The performance of students from the experimental group in the post achievement test showed an increase as compared to how they fared in the pre-test. They also had chalked better results than what was obtained by the control group in the post-test given. This shows that the usage of mobile learning has contributed towards the improved performance in Probability. This certainly is in line with the research conducted by Aloraini (2012) whose statistical results also showed a positive 
impact of using multimedia in the form of mobile learning. This proves that mobile learning in education is indeed an essential tool in bettering learning and performance of students.

The increase in the achievement of students who were exposed to the teaching and learning via mobile learning showed that this medium indeed facilitates learning and helps students reinforce their understanding on the topic. With the integration of mobile learning, the teaching and learning process becomes more effective and relevant as compared to the traditional process. Based on the outcome of this study, it is obvious that mobile learning is a powerful and applicable tool to enhance teaching and learning. The fact that it promotes learning without boundaries certainly provides students with the liberty to learn at their own convenience.

\section{REFERENCES}

Barhoumi, C. (2015) The effectiveness of Whatsapp mobile learning activities guided by activity theory on students' knowledge management. Contemporary Educational Technology, 6(3), 221-238.

Cheung, W.S., Hew, K.F., \& Ng, S.L. (2008). Towards an understanding of why students contribute in asynchronous online discussion. Journal of Educational Computing Research, 38(1), 29-50.

Chu, H.C. (2013). Potential negative effects of mobile learning on students' learning achievement and cognitive load - A format assessment perspective. Educational Technology \& Society, 17(1), 332-344.

Connelly, L.M. (2008). Pilot studies. Medsurg Nursing, 17(6), 411-2.

Connor, T. (1997). Using learning styles to adapt technology for higher education. Retrieved from the Indiana State University website: http://web.indstate.edu/ctl/styles/learning.html

Crossman, A. (2014). Cluster sample. Retrieved from the ThoughtCo. website: https://www.thoughtco.com/cluster-sampling-3026725

Engestrom, Y. (1987). Learning by expanding: An activity-theoretical approach to developmental research. Helsinki, Finland: Orienta-Konsulit Oy.

Gikas, J., \& Grant, M.M., (2013). Mobile computing devices in higher education: Student perspectives on learning with cellphones, smartphones and social media. Internet and Higher Education, (19), 18-26.

Hwang, G.J., \& Chang, H.F. (2011) A formative assessment-based mobile learning approach to improving the learning attitudes and achievements of students. Computers \& Education, 56(4), 1023-1031.

Kadar Abdillahi Barreh, \& Zoraini W.A. (2015). A Framework for Mobile Learning for Enhancing Learning in Higher Education. Malaysian Online Journal of Educational Technology. 3(3).

Kimberlin, C.L., \& Winterstein, A.G., (2008). Validity and reliability of measurement instruments used in research. Am J Health Syst Pharm, 65(23), 2276-84.

Litchfield, A. (2007). Directions for m-learning research to enhance active learning. Paper presented at ASCILITE. Singapore.

Looi, C.K., Seow, P., Zhang, B., So, H.J., Chen,W., \& Wong, L.H. (2010). Leveraging mobile technology for sustainable seamless learning : A research agenda. British Journal of Educational Technology, 41(2), 154-169.

Lunsford, B.R. and Lunsford, T.R. (1995). Research forum: The research sample. Part 1: Sampling, 7(3), 105-112.

McDevitt, T. M., \& Ormrod, J. E. (2013). Child development and education. Pearson International Edition (5th ed.). Upper Saddle River, New Jersey: Pearson.

Muasaad Alrasheedi. (2014). Proceedings of the World Congress on Engineering and Computer Science (1) WCECS

Notar, C.E., Zuelke, D.C., Wilson,J.D., \& Yunker, B.D. (2004). The table of specifications: insuring accountability in teacher made tests. Journal of Instructional Psychology, 31(2).

Sara Aloraini (2012). The Impact of Using Multimedia on Students' Academic Achievement in the College of Education at King Saud University. Journal of King Saud University, (24), 75-82.

Sekaran, U. (2000). Research Method for Business: A Skill Building Approach, John Wiley and Sons, Inc.

Syed Roohullah Jan, Farman Ullah, Hashim Ali, \& Fazlullah Kahn. (2016). Enhanced and Effective Learning through Mobile Learning : An Insight into Students 
Perception of Mobile Learning at University Level. International Journal of Scientific Research in Science, Engineering and Technology. 2(2), 674-681.

Traxler, J. (2007). Defining, Discussing and Evaluating Mobile Learning. International Review of Research in Open and Distance Learning, 8(2), 346-875.

Traxler, J. (2009). Learning in a Mobile Age. International Journal of Mobile and Blended Learning, 1(1), 1-12. 